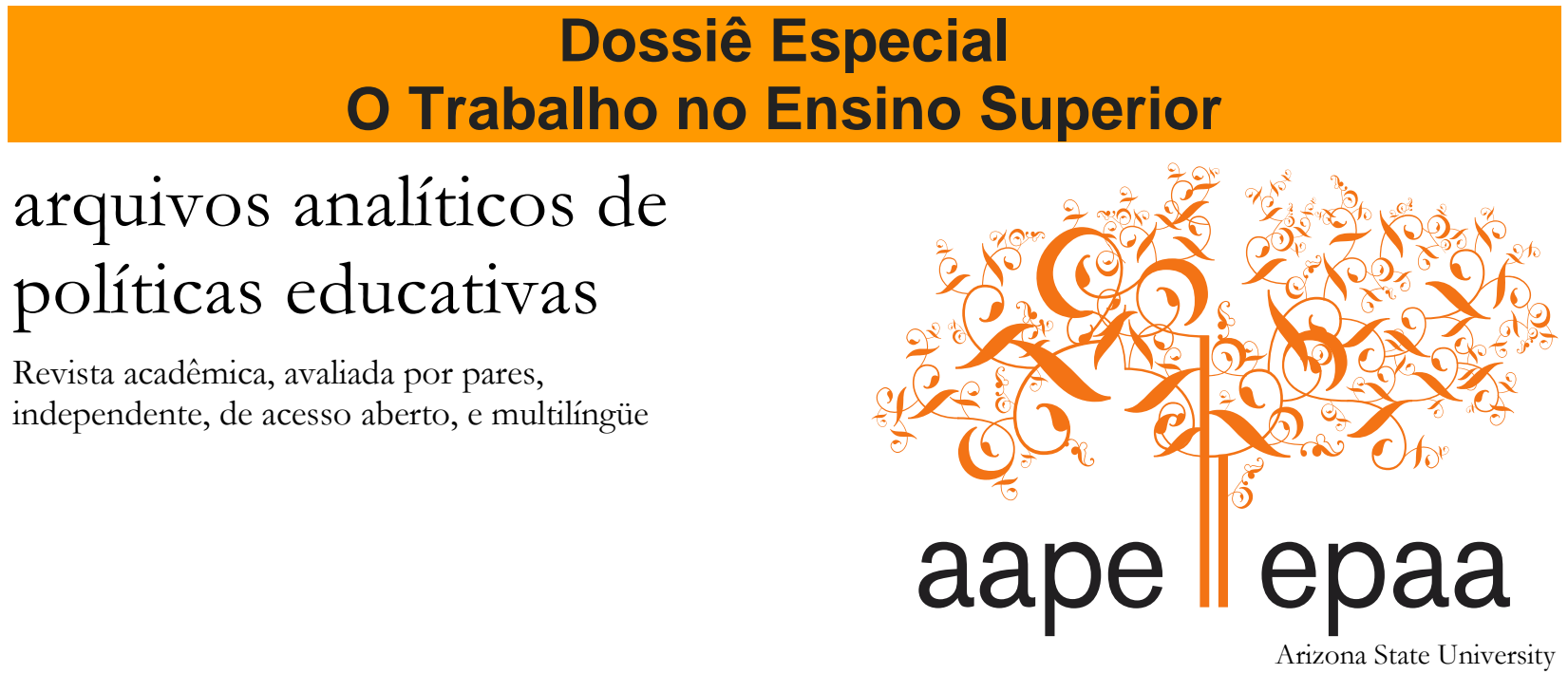

Volume 28 Número $15 \quad 20$ de janeiro de 2020

ISSN 1068-2341

\title{
Trabalho Docente Instrumentalizado na Política de Formação de Professores no Brasil: Uma Abordagem Histórica e Teórico-Filosófica
}

\author{
Roberto Francisco de Carvalho \\ Universidade Federal do Tocantins - UFT \\ Rosilene Lagares \\ Universidade Federal do Tocantins - UFT \\ Doracy Dias Aguiar de Carvalho \\ Universidade Federal do Tocantins - UFT-UNB \\ Brasil
}

Citação: de Carvalho, R. F., Lagares, R., \& Aguiar de Carvalho, D. D. (2020). Trabalho docente instrumentalizado na política de formação de professores no Brasil: Uma abordagem histórica e teórico-pilosófica. Arquivos Analíticos de Políticas Educativas, 28(15).

https://doi.org/10.14507/epaa.28.4858 Este artigo faz parte do dossiê especial, O trabalho na educaşão superior, editada por Deise Mancebo, Kátia Maria Teixeira Santorum, Denise Bessa Léda, e Carla Vaz dos Santos Ribeiro

Resumo: O texto aborda a política/gestão de formação de professores no Brasil e ancora-se nos resultados da pesquisa "Política/gestão da formação de professores na perspectiva da filosofia da práxis: tensão entre as perspectivas econômico-corporativa e ético-política". O objetivo da investigação da qual resulta esta reflexão consistiu em explicitar - sob o ponto de vista histórico e teórico-filosófico - a instrumentalização do trabalho docente no processo de formação de professores, sem desconsiderar a existência teórico-prática da perspectiva formativa 
emancipadora fundamentada nos princípios ético-políticos e da filosofia da práxis. $\mathrm{Na}$ consecução do objetivo proposto utilizamos o referencial teórico-metodológico histórico e crítico-dialético e o projeto foi desenvolvido por meio das pesquisas bibliográfica e empíricodocumental. Neste artigo, objetivamos discutir os fundamentos da política/gestão de formação dos professores brasileiros na perspectiva instrumental e sua relação com o trabalho docente. A pesquisa revelou, sob o ponto de vista histórico e teórico-filosófico, que a formação de professores no Brasil, tendencialmente, ocorreu na perspectiva instrumental, com a priorização da dimensão técnico-pedagógica em relação à político-cultural. Todavia, a instrumentalização do trabalho docente não se constitui de forma linear ou desprovida das contradições tensionadas pelas forças que vêm lutando por uma educação e formação de professores numa perspectiva substantiva, libertária e emancipadora.

Palavras-chave: Política/gestão de formação de professores; Abordagem histórico-filosófica; Instrumentalidade do trabalho docente

\section{Teaching work instrumentalized Brazilian teacher training policy: A historical and theoretical-philosophical approach}

Abstract: This text deals with policy/management of teacher training in Brazil and is anchored in the results of the research project, "Policy/management of teacher training in the perspective of the philosophy of praxis: Tension between the economic-corporate and ethical-political perspectives". The research aimed to explain the instrumentalization of the teaching work in the teacher training process from a historical and theoretical-philosophical point of view, without disregarding the theoretical-practical existence of the philosophy of praxis and of the emancipatory formative perspective based on the ethical-political principles. In achieving the proposed objective, we used the historical-methodological and critical-dialectical frame of reference, and the project was developed through bibliographical and empirical-documentary research. In this article, we aim to discuss the fundamentals of the training policy/management of Brazilian teacher education in the instrumental perspective, as well as their relationship with the teaching work. The research revealed that teacher education in Brazil tended to occur from the instrumental perspective, with the prioritization of the technical-pedagogical dimension in relation to the political-cultural prioritization. However, the instrumentalisation of the teaching work is not linear or devoid of contradictions among the forces that have been fighting for the education and training of teachers with a substantive, libertarian and emancipatory perspective.

Keywords: Policy/management; teacher training; Historical-philosophical approach; Instrumentality of the teaching work

\section{Trabajo docente instrumentalizado en la política de formación docente en Brasil: Un enfoque histórico y teórico-filosófico}

Resumen: El texto aborda la política/gestión de formación de profesores en Brasil y se basa en los resultados de la investigación "Política/gestión de la formación de profesores en la perspectiva de la filosofía de la praxis: tensión entre las perspectivas económico-corporativa y ético-política." El objetivo de la investigación de la que resulta esta reflexión consistió en explicitar - desde el punto de vista histórico y teórico-filosófico - la instrumentalización del trabajo docente en el proceso de formación de profesores, sin desconsiderar la existencia teórico-práctica de la perspectiva formativa emancipadora fundamentada en los principios éticopolíticos y de la filosofía de la praxis. En la consecución del objetivo propuesto utilizamos el referencial teórico-metodológico histórico y crítico-dialéctico y el proyecto fue desarrollado por medio de las investigaciones bibliográfica y empírico-documental. En este artículo, objetivamos discutir los fundamentos de la política/gestión de formación de los profesores brasileños en la 
perspectiva instrumental y su relación con el trabajo docente. La investigación reveló desde el punto de vista histórico y teórico-filosófico que la formación de profesores en Brasil, tendencialmente, ocurrió en la perspectiva instrumental, con la priorización de la dimensión técnico-pedagógica en relación a la político-cultural. Sin embargo, la instrumentalización del trabajo docente no se constituye de forma lineal o desprovista de las contradicciones tensadas por las fuerzas que vienen luchando por una educación y formación de profesores desde una perspectiva sustantiva, libertaria y emancipadora.

Palabras-clave: Política/gestión de la formación docente; Enfoque histórico-filosófico; Instrumentalidad del trabajo docente

\section{Introdução}

Neste artigo, que é parte dos resultados do projeto de pesquisa, "Política/gestão da formação de professores na perspectiva da filosofia da práxis: tensão entre as perspectivas econômico-corporativa e ético-política, tratamos os fundamentos da política/gestão de formação de professores abrangendo o trabalho docente numa abordagem histórica e teórico-filosófico." O estudo foi realizado a partir dos trabalhos publicados sobre a política/gestão de formação de professores, entre 1995 e 2014, nos periódicos brasileiros: Revista Brasileira de Educação; Revista Brasileira de Estudos Pedagógicos; Educação e Filosofia; e Revista Digital Arteぬ Educação - Cultura - Formação - Comunicação - Produção.

No período supracitado, que abrangeu os governos de Fernando Henrique Cardoso e Luiz Inácio Lula da Silva, foram realizadas reformas que modificaram significativamente as áreas da educação e da formação de professores, norteadas por uma racionalidade financeira - mesmo que tensionada pela racionalidade democrático-popular orientadora da educação pública - abrangendo os movimentos Educação para Todos (1995-2005) e Todos pela Educação (2006-2014). Selecionamos a Revista Brasileira de Educação, da Associação Nacional de Pós-Graduação e Pesquisa em Educação (ANPED), em razão do escopo de sua publicação, que compreende o universo das pesquisas resultantes de estudos no âmbito da pós-graduação brasileira. A seleção dos demais periódicos, Revista Brasileira de Estudos Pedagógicos; Revista Educação e Filosofia; e Revista Digital Arte\& Educação [...], deveu-se ao fato destes publicarem estudos resultantes de pesquisas que se aproximam da produção teórico-prática dos três cursos de licenciaturas, respectivamente, Pedagogia, Filosofia e Arte, base empírica do projeto de pesquisa que originou o presente artigo.

No projeto do qual resultou este trabalho investigamos a política/gestão de formação de professores na perspectiva da filosofia da práxis, tendo a educação como arena de luta ético-política ${ }^{1}$. Assim, especificamente no presente texto, indagamos: quais são os fundamentos da política/gestão de instrumentalização do trabalho docente no processo de formação de professores no Brasil?

Com o intuito de responder a essa pergunta, buscamos, em geral, discutir os fundamentos da formação dos professores brasileiros na perspectiva instrumental tensionada pela dimensão política. No estudo realizado a respeito da formação de professores brasileiros por meio da pesquisa nos

\footnotetext{
${ }^{1}$ Processo formativo do professor que tem como ponto de partida a prática social - síntese provisória das relações sociais, vislumbrada por um devir histórico - que é problematizada utilizando-se da instrumentalidade teórico-prática existente e expressa, em grande medida, nas dimensões econômicocorporativa e técnico-pedagógica que tem a eficiência e a eficácia como critério educacional. Tal processo objetiva, entretanto, chegar à catarse, momento superior da formação caracterizado pela dimensão éticopolítica e político-cultural orientada pelos critérios de efetividade e relevância social que tem como ponto de chegada o horizonte da prática social em constante movimento e possível de transformação.
} 
periódicos supracitados, objetivamos, especificamente, apreender os fundamentos da formação calcados em valores econômico-corporativos; e, no caso das reflexões desse texto, explicitar, sob o ponto de vista histórico e teórico-filosófico, a instrumentalização do trabalho docente no processo de formação de professores sem desconsiderar a existência teórico-prática da perspectiva formativa emancipadora fundamentada nos princípios ético-políticos e da filosofia da práxis.

$\mathrm{Na}$ consecução do objetivo proposto, tomando como referencial teórico-metodológico o materialismo histórico-dialético (Marx, 1982, 1985), desenvolvemos o estudo utilizando o instrumento auxiliar de pesquisa na perspectiva dialética da análise de conteúdo abrangendo três momentos ou fases: análise prévia; exploração do material; e tratamento dos resultados, explicitado na inferência e interpretação (Bardin, 1977).

$\mathrm{Na}$ análise prévia, fizemos a leitura dinâmica dos artigos sobre a formação de professores publicados nos quatro periódicos brasileiros, buscando uma primeira organização do material de estudo em conformidade com os objetivos da pesquisa. Essa foi a fase em que buscamos compreender a política/gestão de formação de professores no Brasil pelas diversas pesquisas produzidas sob o ponto de vista histórico e teórico-filosófico, tendo em vista identificar traços formativos instrumentalizadores ou emancipadores dos professores em formação. Nessa fase, foram lidos os resumos dos periódicos, base empírica da pesquisa, categorizando-os em sub temáticas, com destaque para a formação de professores.

Partindo do material previamente organizado e anteriormente mencionado, passamos à fase da exploração por meio da leitura integral dos artigos que trataram diretamente da política/gestão de formação de professores sob o ponto de vista histórico e teórico-filosófico, posteriormente, classificando e agrupando os achados nas categorias de análise formação instrumental ou substantiva.

$\mathrm{Na}$ fase do tratamento dos resultados obtidos, procuramos aprofundar a análise visando superar a compreensão aparente e superficial do objeto de estudo acerca da formação de professores no Brasil: a instrumentalização do trabalho docente, explicitada numa abordagem histórica e teóricofilosófica, conforme exposto nos itens seguintes.

Em termos quantitativos, a pesquisa em geral abrangeu o conjunto de oitenta artigos que abordaram a temática da política/gestão de formação de professores no Brasil. Desse total geral 32 $(40 \%)$ trataram da formação inicial, $18(22 \%)$ da formação continuada ou em serviço e $30(38 \%)$ da discussão geral sobre a formação de professores por meio de reflexão histórica, filosófica, cultural e político-educacional.

Depreendemos da pesquisa realizada que os cursos de formação de professores brasileiros, conforme revelação dos 80 artigos analisados ${ }^{2}$, em sua grande maioria (73\%) têm priorizado as dimensões instrumentais/econômico-corporativa, centradas nos critérios de eficiência econômicoadministrativa e eficácia pedagógico. Os outros $27 \%$ dos artigos estudados revelaram reflexões sobre cursos ou experiências formativas que privilegiam as dimensões substantivas/ético-política, evidenciadoras de critérios de efetividade política e relevância cultural.

Dos 30 artigos que trataram da formação de professores, em geral, cinco (17\%) referem-se aos aspectos históricos, oito $(27 \%)$ aos aspectos filosóficos, treze $(47 \%)$ às políticas educacionais e quatro $(13 \%)$ aos aspectos culturais. Desses artigos, $23(77 \%)$ apontam para a dimensão formativa instrumental/econômico-corporativa, centrada nos critérios de eficiência econômico-administrativa

\footnotetext{
${ }^{2}$ Esclarecemos que no presente estudo não fizemos a avaliação dos artigos fonte da pesquisa - que, no nosso entendimento, trazem reflexões valiosas sobre a temática - e nem categorizamos a filiação teórica dos pesquisadores, mas buscamos, por meio deles, apreender o sentido da formação/participação de professores no Brasil.
} 
e eficácia pedagógica e sete (23\%) referem-se à dimensão formativa substantiva/ético-política, caracterizada pelos critérios de efetividade política e relevância cultural.

\section{A Instrumentalização do Trabalho Docente na Política/Gestão de Formação de Professores: Abordagem Histórica e Teórico-filosófica}

A análise realizada neste texto ${ }^{3}$ abarca a discussão de dez artigos publicados nas revistas pesquisadas ${ }^{4}$, sendo cinco de cunho histórico e cinco teórico-filosófico, e visa explicitar o processo formativo de professores que: focaliza o indivíduo submetido/adaptado à esfera público/privada, cuja participação ocorre na perspectiva da democracia mínima centrada mais na execução do que na tomada de decisões; prioriza a dimensão técnico-administrativa e pedagógica; explicita a desconexão teoria e prática; e evidencia-se, em grande medida, de modo acrítico/instrumental.

\section{Formação de Professores Brasileiros: Aspectos Históricos}

Sob o ponto de vista histórico, os estudos de Tanuri (2000), Brzezinski (2001), Mortatti (2008), Saviani (2009) e Mcculloch (2012) apontam que desde o império - passando por diversas fases da República - a instrumentalização do trabalho docente na política/gestão de formação de professores no Brasil, em grande medida, direcionou-se ao indivíduo visando sua submissão e adaptação à esfera público/privada, em que a participação está mais centrada na execução do que no processo de tomada de decisões, portanto, sustentada na perspectiva da democracia mínima..

Tomando por referência Tanuri $(2000)^{5}$, fica demonstrado que durante o Império, entre 1822 e 1889, na formação da escola primária normal, de iniciativa privada, foi implantado o formato francês de educação devido à sua aproximação com a tradição colonialista, base da formação das elites brasileiras na perspectiva cultural europeia. Essa perspectiva formativa continuou na primeira república (1889-1930), momento em que a formação na Escola Normal perseguiu uma estrutura curricular que enfatizou as matérias científicas e a cultura de tipo enciclopédica, de abordagem ampla dos problemas educacionais.

Entre 1930 e 1970, a educação e a política/gestão de formação de professores, sob a influência da Escola Nova, inspirada em John Dewey, passa a abordar os problemas educacionais

\footnotetext{
${ }^{3}$ Como buscamos apreender a perspectiva histórica e teórico-filosófica da formação de professores no Brasil utilizando-nos do que foi produzido e publicado nos periódicos mencionados, transcrevemos, neste artigo, algumas citações diretas dos autores pesquisados por entender que estas evidenciam o que este estudo pretendeu demonstrar acerca da concepção e lógica da política/gestão da formação de professores no Brasil.

${ }^{4}$ Dentre as diversas fontes existentes acerca da formação docente no Brasil, em uma perspectiva histórica, destacamos para além dos textos analisados neste artigo, algumas das principais referências primárias como: Brzezinski (1987); Candau (1987; 1997); Catani (1997); Cavalcante (1994); Gatti (1997); Mello (2003); Menezes (1996); Nóvoa (1995); Saviani (2008); Rugiu (1998); Silva (1991); e Tardif (2002).

${ }^{5}$ Acerca da história da formação de professores no Brasil, considerando os diversos períodos da história da educação, ver, também, os trabalhos de Brzezinski e Garrido (2001) que abordam, dentre outras temáticas, a formação inicial abrangendo o Curso Normal, o Curso de Pedagogia e as Licenciaturas, bem como a formação continuada. Outra periodização importante a ser referenciada é a desenvolvida por Saviani (2009), que examina a trajetória da formação de professores no Brasil, em seis períodos: ensaios intermitentes de formação de professores (1827-1890); estabelecimento e expansão do padrão das Escolas Normais (18901932); organização dos Institutos de Educação (1932-1939); organização e implantação dos Cursos de Pedagogia e de Licenciatura e consolidação do modelo das Escolas Normais (1939-1971); substituição da Escola Normal pela Habilitação Específica de Magistério (1971-1996); Advento dos Institutos Superiores de Educação, Escolas Normais Superiores e o novo perfil do Curso de Pedagogia (1996-2006).
} 
sob o ponto de vista técnico-científico articulando os aspectos teóricos e práticos internos e externos ao ambiente escolar na lógica da escola renovada. No Brasil República, de 1970 a 1980, a escola também foi estruturada em função da esfera privada.

Entre as reformas do regime militar, a reordenação do ensino superior, decorrente da Lei 5.540/68, teve como consequência a modificação do currículo do curso de Pedagogia, fracionando-o em habilitações técnicas, para formação de especialistas, e orientando-o tendencialmente não apenas para a formação do professor do curso normal, mas também do professor primário em nível superior, mediante o estudo da Metodologia e Prática de Ensino de $1^{\circ}$ Grau. (Tanuri, 2000, p. 80)

Seguindo caminho semelhante, Mortatti (2008) contribui com a compreensão da história da formação de professores no Brasil apresentando "reflexões sobre a formação do professor responsável pela alfabetização de crianças, desde o final do século 19 até os dias atuais, e sua relação com a história da alfabetização em nosso país.” (p. 467) O texto discute o processo de formação vinculado às concepções de educação em disputa que se efetivaram no contexto histórico brasileiro, a saber: educação humanista tradicional; educação nova; educação construtivista e o seu desdobramento na educação do aprender a aprender. Revela a dualidade da educação brasileira diferenciada conforme a classe social a que se destina, em geral, ligada à ilustração brasileira em um primeiro momento e, posteriormente, vinculada ao mundo do trabalho, a partir do processo de industrialização e modernização do Estado brasileiro.

Dos trabalhos analisados, em seu conjunto, podemos deduzir que a formação da classe trabalhadora, incluindo os professores, centrou-se numa perspectiva instrumental, pouco ligada à inserção sociocultural e a uma participação efetiva. Esse processo formativo, conforme Mortatti (2008), abrange a educação humanista tradicional até a década de 1930 (de participação limitada dos educandos em geral); educação nova pós-1930 (cuja participação nas atividades formativas é o centro do processo de ensino); educação construtivista pós-1980 e educação do aprender a aprender pós-1990 (que tem como pressuposto a participação do educando na construção do conhecimento). No caso brasileiro, relacionado a essa última perspectiva, tal participação acabou por converter-se em ativismo pedagógico, tendo em vista que o processo de ensino subordinou-se ao ritmo de aprendizagem dos alunos e às condições socioculturais, tendo a educação escolar como uma forma de adequação e conformação à realidade social vigente considerada naturalmente imutável.

Nessa lógica formativa - em parte, inspirada em modelos externos de educação e formação -, não é difícil deduzir que, em geral, o professor brasileiro, principalmente o da escola básica, pouco participou do seu processo formativo. Ele foi, assim, submetido às decisões externas a sua vida profissional histórica no quesito formativo, seja guiado pelo Estado ou pelos interesses privados/mercantis. No entendimento de Mcculloch (2012), ampliando o leque das análises, a ausência da história da educação nos cursos de formação de professores no mundo contribui para a formação de um professor cuja participação é pouco efetiva e relevante no âmbito social. Essa amnésia histórica atinge as políticas de governo para a área demonstrando limitada consciência acerca da história pregressa e repercute negativamente na predisposição e interesse político para compreender o presente, com suas mudanças, continuidades e tensões.

Do raciocínio aventado anteriormente, fica evidenciado que a dimensão instrumental técnico-administrativa e pedagógica vem sendo priorizada/buscada na política/gestão de formação dos professores e repercute na instrumentalização do trabalho docente na mesma lógica do que ocorre com os trabalhadores, em geral. Os estudos de Tanuri (2000), Brzezinski (2001) e Saviani (2009) são fontes essenciais para demonstrar tal caracterização no contexto histórico da educação brasileira. 
Saviani (2009) argumenta que, em 1827, com a criação das Escolas de Primeiras Letras, a formação de professores também aparece. O ensino deveria ocorrer por meio do método mútuo e os professores deveriam " [...] ser treinados nesse método, às próprias custas, nas capitais das respectivas províncias, [...] colocada aí a exigência de preparo didático, embora não se faça referência propriamente à questão pedagógica.” (Saviani, 2009, p. 144)

Com o Ato Adicional de 1834 a instrução primária foi descentralizada às províncias sendo adotada a formação de professores de tendência europeia acerca das Escolas Normais. A política/gestão de formação de professores naquele período histórico sinalizava priorizar a dimensão didático-pedagógica, mas, de fato, efetivou-se o predomínio dos conhecimentos/conteúdos a serem transmitidos nas escolas de primeiras letras (Saviani, 2009).

Em 1854, houve a tentativa, sem sucesso, de reformar a educação e de substituir a formação nas Escolas Normais por professores adjuntos para atuar nas escolas desempenhando a função de ajudantes do regente de classe, com foco nas matérias e práticas de ensino (Saviani, 2009). Entretanto, mais uma vez a tentativa de articular conteúdo e forma não encontrou forças para se efetivar, ficando no campo da vontade, sem criar as condições para sua concretização.

Ainda segundo Saviani (2009), entre 1890 e 1932, as Escolas Normais foram expandidas, com foco nos conteúdos e nas práticas de ensino. Os reformadores de plantão defendiam que a formação dos professores deveria abranger os modernos processos pedagógicos e o conhecimento científico necessários ao alcance da eficácia pedagógica e educacional. A reforma, contudo, novamente não vigorou e continuou o modelo de transmissão de conhecimento.

Depreendemos da discussão de Saviani (2009) que - com o advento dos Institutos de Educação, sob a inspiração da Escola Nova - a tentativa de formação de professores, com foco na educação, foi retomada, transformando a Escola Normal em Escola de Professores, cujo currículo incluía Biologia, Sociologia, Psicologia, História da Educação e Introdução ao Ensino. Mas com a implantação dos cursos de Pedagogia e Licenciaturas (1939 e 1971) ocorreu o processo formativo 3+1 em que 3 anos eram dedicados aos conteúdos específicos e 1 ano aos pedagógicos.

Entre 1971 e 1996, com a lei 5692/71 (Brasil, 1971), a Escola Normal foi substituída pela Habilitação Específica em Magistério. A política de formação de professores para o ensino primário reduziu-se à habilitação dispersa e previu - para as quatro últimas séries do ensino de $1^{\circ}$ grau e para o ensino de $2^{\circ}$ grau - a formação em nível superior, em cursos de licenciatura curta/plena. Em 1980 passou a existir um movimento que adotou a docência como central no processo de formação dos trabalhadores da educação. A promulgação da Lei 9394/96 (Brasil, 1996), contudo, não supriu a expectativa, ocorrendo o nivelamento da formação por baixo: “[...] os institutos superiores de educação emergem como instituições de nível superior de segunda categoria, provendo uma formação mais aligeirada, mais barata, por meio de cursos de curta duração.” (Saviani, 2009, p. 148). ${ }^{6}$

Com o advento da reforma educacional de 1990 e, no seu bojo, a promulgação da Lei 9394/1996 (Brasil, 1996), as proposituras de formação de professores, tendo como centralidade a docência, abrangeram: a pesquisa-ação, a integração, a flexibilidade, a multidisciplinaridade, a contextualização, o construtivismo, a pedagogia do aprender a aprender, práxis orientada pela prática, experiências pessoais e história de vida (Brzezinski, 2001). Referimo-nos a uma perspectiva de formação que tem deslocado o foco formativo de uma sólida formação teórica fundada na reflexão filosófica, sociológica e histórico-política para a prática formativa. Lembramos, entretanto, que essa tendência formativa não inclui somente o caso brasileiro. Conforme Mcculloch (2012), desde o início da década de 1980, em diversos países, a história da educação ainda tinha presença

${ }^{6}$ Mortatti (2008) também evidencia a dimensão técnico-pedagógica da formação do professor alfabetizador vinculada a quatro momentos: o primeiro (1876-1890); o segundo (1890-1920); o terceiro (1920-1970); e o quarto (1980 aos dias atuais). 
garantida nos cursos de formação de professores. Para esse autor, referência da nossa interlocução nessa reflexão, na década de 1990 passou a existir uma tendência de que a formação de professores, deveria fundamentar-se nas práticas de ensino em vez das teorias acadêmicas.

Tomando como exemplo o caso da política/gestão de formação dos professores alfabetizadores brasileiros, o processo seguiu o viés formativo que tem como principal característica a hegemonia da perspectiva construtivista: "[...] nesse sentido, o foco do processo de alfabetização está no como a criança aprende a língua escrita" (Mortatti, 2008, pp. 472-473), sendo necessário dar mais instrumentalidade ao trabalho docente.

Uma das fraturas indicadas por Gramsci (2006) no âmbito do debate sobre a filosofia da práxis refere-se à relação teoria e prática ${ }^{7}$. Pensando a educação no contexto histórico, tal relação tem a história como um dos fundamentos da verdade. Referindo-se à política/gestão de formação de professores, a desconexão da formação com a história da educação consiste em uma fratura profunda entre a vida no momento presente e sua história pregressa.

A respeito da relação formação e história, Mcculloch (2012) cita um curso ministrado por Durkheim no qual ele considera a relação teoria e prática e o contexto histórico em longo prazo, necessários para se processar as mudanças educacionais. Ainda segundo a autora, para Durkheim (1977), em um curso de formação a teoria da educação é fundamental no sentido de estudar o passado para antecipar o futuro e entender o presente. Entender a história da educação visando assegurá-la como direito, nos termos de Durkheim (1977), para a autora em pauta, é compreender o homem em uma totalidade histórica, pois "[...] o presente era meramente "uma extrapolação do passado, do qual não pode ser cortado sem perder a maior parte de sua significação.”' (p. 122).

A partir do final da década de 1980, a história da educação mundial passou a ser excluída do “[...] currículo de formação de professores, juntamente a outras abordagens teóricas ou intelectuais não consideradas relevantes na aquisição de habilidades e métodos de ensino.” (Mcculloch, 2012, p. 123). Tal perspectiva coincide com a pedagogia do aprender a aprender, de 1990, mas não se reduz a ela, visto que os estudos têm demostrado uma desconexão teoria e prática, também, nas pedagogias tradicional, da Escola Nova, tecnicista e construtivista.

Acerca da desconexão teórico-prática, ao analisar a política/gestão de formação dos professores alfabetizadores brasileiros, Mortatti (2008) revelou, no âmbito da Escola Humanista tradicional de formação geral, uma preocupação com os conteúdos a serem ensinados (teoria), mas que não teve relação direta com a realidade e interesses imanentes ao homem moderno. A formação centralizou-se na figura do professor que teve o aluno praticamente como ouvinte, com foco nos estudos da cultura geral realizado na perspectiva do método de alfabetização sintético, por meio de instruções prescritivas e tensionados pelo método de alfabetização analítico.

A Escola Nova ou da cientificização da educação/pedagogia - nos moldes das ciências naturais, caracterizadas pela experimentação e verificação e complementadas pelo suporte dos conhecimentos de Psicologia - teve como centralidade do processo formativo o método do professor no qual o aluno assume um papel ativista na sua formação. Especificamente sobre os professores alfabetizadores, a formação ocorreu, essencialmente, voltada para a prática de ensino em que se evidenciou a observação e experimentação. Já na perspectiva do construtivismo, segundo a autora em tela, há um deslocamento do método de como ensinar para como aprender. $\mathrm{O}$ ativismo do aluno é valorizado, tendo o professor como mediador, embasado pela psicologia e pela didática construtivista.

Sem desconsiderar os aspectos formativos emancipadores podemos dizer, conforme os artigos analisados, que a política/gestão de formação de professores no Brasil, no aspecto histórico,

${ }^{7}$ A desconexão teoria e prática no processo de formação dos professores brasileiros sob o ponto de vista da história da educação brasileira é abordada com também por Tanuri (2000) e Brzezinski (2001). 
tendencialmente ocorreu na perspectiva instrumental na qual a dimensão técnico-pedagógica do trabalho docente foi priorizada em relação à político-cultural. O trabalho de Tanuri (2000) a esse respeito revelou que, no Império (1822-1889), o processo formativo ocorreu na perspectiva prática, sem a preocupação com a base teórica. Esse processo abarcou a formação dos professores adjuntos; professores das primeiras letras, utilizando-se do método de ensino mútuo para a instrução das corporações militares; e professores das Escolas Normais, tendo como centralidade os métodos de ensino de natureza prescritiva.

Seguindo as trilhas dos estudos de Tanuri (2000), no período da República (1889-1930), a formação técnico-profissional foi evidenciada no âmbito da Metodologia do Ensino. Entre $1930 \mathrm{e}$ 1970 a formação do professor com foco em uma "[...] abordagem estritamente técnica tem sido apontada como responsável por uma visão ingênua e tecnicista da educação, isolada de seu contexto histórico-social [...]” (Tanuri, 2000, p. 72), enfatizando os conteúdos pedagógicos de caráter científico com procedimentos didáticos, sob o verniz da neutralidade.

A despeito do advento da Lei 4024/1961 (Brasil, 1961), continuou o distanciamento entre a sociedade e a educação. Imperou na referida Lei a ausência de disciplinas voltadas para a análise das questões educacionais e o fortalecimento da formação com base nos conteúdos tidos como universais, científicos e apresentados travestidos de uma certa neutralidade. No período, pós 1964, seguindo uma lógica formativa parecida, os dirigentes educacionais buscaram

[...] 'modernizar' a prática docente, para a 'operacionalização' dos objetivos instrucionais e comportamentais -, para o 'planejamento, e coordenação e o controle' das atividades, para os 'métodos e técnicas' de avaliação, para a utilização de novas tecnologias de ensino, então referentes, sobretudo, a 'recursos audiovisuais'. Tratava-se de tornar a escola 'eficiente e produtiva', ou seja, de torná-la operacional com vistas à preparação para o trabalho, para o desenvolvimento econômico do país, para a segurança nacional. (Tanuri, 2000, p. 79)

Ainda de acordo com Tanuri (2000), no período entre 1970 e 1980, em nome de um processo formativo mais flexível, a Escola Normal foi esvaziada, desmontada e desestruturada e, por descaracterização, perdeu a sua identidade, em grande medida, marcada pelos componentes metodológicos instrumentais. A autora demonstra que a promessa da flexibilidade e integração da política/gestão de formação de professores não se concretizou e passou a sofrer inúmeras críticas na década de 1980, baseadas numa análise de natureza sociológica, “[...] principalmente no quadro das teorias do conflito e teorias críticas em geral, de modo que o fracasso dos modelos escolares não é analisado mais em função de abordagens psicológicas ou tecnicistas, ou de aspectos exclusivamente legislativos ou técnicos." (Tanuri, 2000, p. 82).

A partir dessas críticas apareceram várias propostas de formação de professores que vão compor a política/gestão educacional da década de 1990, em defesa da pesquisa-ação, integração, flexibilidade, multidisciplinaridade, contextualização, construtivismo, práxis entendida como prática, espaço de formação e história de vida. Essa foi a lógica de formação que norteou a Lei 9394/96 (Brasil, 1996), ficando estabelecido no art. 62 que "[...] a formação de docentes para atuar na educação básica far-se-á em nível superior, em curso de licenciatura, de graduação plena, em universidades e institutos superiores de educação [...]."

Acerca da política/gestão da formação de professores no Brasil, situada no contexto histórico, confluindo para a sua regulamentação na LDB 9394/96, é relevante destacar as contribuições de Mendes (2002), Silva Jr. (2003) e Gatti (2012) que têm estudado a temática sem perder de vista o contexto econômico, social e político mais amplo em articulação com a realidade dos sistemas educacionais e os ambientes escolares. 
Frente ao exposto anteriormente, inferimos que, historicamente, as preocupações voltaramse para a dimensão técnico formativa, embora também existam, em menor intensidade, preocupações com a formação político cultural. Considerando o percurso histórico educacional, embora nos estudos referenciados neste texto tenha havido uma preocupação com a inovação na formação de professores, ainda, permanece uma estrutura formativa tradicional, que vem sendo aprofundada com o aligeiramento formativo dos professores.

Referindo-se ao período pós 1990, o que temos assistido em termos educacionais é a implantação de uma inovação gerencialista que requer um professor flexível e empreendedor, qualificado para preparar os seus educandos a viverem em um mundo incerto e sem perspectiva, em que os aspectos sociais estruturantes são escamoteados pela supervalorização dos elementos de ordem técnica. Com essa intencionalidade, a dimensão técnica é priorizada na formação dos professores brasileiros, ressaltando-se os resultados formativos, e não o processo da formação. Esse processo repercute no trabalho docente, articulado ao trabalho no mundo da produção, em geral, mas com significativa desconexão entre a teoria que defende a formação político cultural e a prática instrumental.

Trata-se, efetivamente, de um processo de formação articulado às mudanças da sociedade capitalista do final do século XX no campo econômico, cultural e político e, nesse escopo, as reformas do Estado e das instituições sociais, como as educacionais. Advém das referidas mudanças a realização da política de educação brasileira ancorada na ideia do deslocamento da formação estruturada no conhecimento científico e na profissionalização de orientação taylorista/fordista para uma perspectiva formativa baseada nos valores mercantis. Nesse sentido, a eficiência e a eficácia norteiam um tipo de individualismo no qual a formação ocorre por meio de um cognitivismo adaptativo, viabilizado pela aprendizagem passiva do sujeito do conhecimento. Participar do processo formativo, nessa perspectiva, tem a conotação de cooperação e colaboração no desenvolvimento da formação inicial e em serviço, e não de uma compreensão histórico-crítica da realidade visando à transformação social.

\section{Formação de Professores Brasileiros: Aspectos Teórico-filosóficos}

Para Saviani (2009), o percurso histórico da política/gestão de formação dos professores no Brasil pode ser, em geral, fundamentado em dois modelos teórico-filosóficos. Esses dois modelos, a exemplo da educação, em geral, realizou-se por meio da desconexão entre a teoria e a prática, entre formação com base nos conteúdos específicos e os didático-pedagógicos, ou seja, o

[...] modelo dos conteúdos culturais-cognitivos: para este modelo, a formação do professor se esgota na cultura geral e no domínio específico dos conteúdos da área de conhecimento correspondente à disciplina que irá lecionar; [...] modelo pedagógicodidático: contrapondo-se ao anterior, este modelo considera que a formação do professor propriamente dita só se completa com o efetivo preparo pedagógicodidático. (Saviani, 2009, pp. 148-149. Grifos do autor)

Na preparação do professor primário nas escolas normais mencionadas no item anterior se fez presente, em maior medida, o modelo pedagógico-didático, mas, no âmbito das universidades, tem ocorrido uma luta entre esses dois modelos no que se refere à formação de professores.

De um lado está o modelo para o qual a formação de professores propriamente dita se esgota na cultura geral e no domínio específico dos conteúdos da área de conhecimento correspondente à disciplina que o professor irá lecionar. Considera-se que a formação pedagógico-didática virá em decorrência do domínio dos conteúdos do conhecimento logicamente organizado, sendo adquirida na própria prática docente ou mediante mecanismos do tipo treinamento em serviço. [...] A esse 
modelo se contrapõe aquele segundo o qual a formação de professores só se completa com o efetivo preparo pedagógico-didático. Em consequência, além da cultura geral e da formação específica na área de conhecimento correspondente, a instituição formadora deverá assegurar, de forma deliberada e sistemática por meio da organização curricular, a preparação pedagógico-didática, sem a qual não estará, em sentido próprio, formando professores. (Saviani, 2009, p. 149)

A política/gestão de formação dos professores brasileiros, nesse sentido, apresenta uma desconexão entre conteúdo e forma, o que acabou por fortalecer a dimensão formativa técnica e a instrumentalização do trabalho docente. A política/gestão de formação de professores analisada sob o ponto de vista teórico-filosófico, que aponta o seu caráter instrumental, em geral, foi abordada no presente estudo por Ghiraldelli Jr. (1997), Devechi e Trevisan (2011), Rocha (2004), Turmina e Shiroma (2014) e Silva (2013).

Depreendemos dos autores mencionados uma certa conformidade acerca do indivíduo adaptado ao contexto social contemporâneo, cuja participação ocorre na perspectiva da democracia mínima centrada mais na execução das tarefas do que nas tomadas de decisões. Nesse sentido, Ghiraldelli Jr. (1997) desenvolve a temática do bom professor no contexto da modernidade e da época contemporânea. O autor, discute a formação de professores, considerando as seguintes fases: o professor segundo o discurso pedagógico humanista; o professor segundo a discussão pedagógica da era da "sociedade do trabalho; e o professor segundo o discurso pedagógico tecnicista. O autor assevera que a ideia de uma formação substantiva - que possibilite uma participação efetiva e autônoma do professor, consciente da racionalidade técnica e do controle do fazer humano - é algo que ficou no passado, no contexto do discurso pedagógico humanista e da sociedade do trabalho. Ele entende que no "[...] mundo atual o cotidiano de todas as atividades e, portanto, também da atividade do professor, está cada vez mais orientado pela razão instrumental.” (p. 246-247).

O texto de Ghiraldelli Jr. (1997) explicita o ideário do bom professor na sociedade contemporânea e esclarece que hoje, mias que outrora, a racionalidade técnica faz parte de tal ideário e do discurso e da prática pedagógica. O autor ressalta que para cada uma das fases mencionadas anteriormente o discurso pedagógico se desenvolve apoiado numa "[...] noção de infância, uma finalidade da educação (e da escola) e [...] um papel destinado ao professor [...]." (Ghiraldelli Jr., 1997, p. 248).

A discussão acerca da relação teoria e prática passa por compreender esse tripé de noções acerca da infância, educação/escola e professor. Assim, para Ghiraldelli Jr. (1997), no estágio do discurso humanista, tendo a noção de infância como a etapa da vida - na qual a criança se aproximaria do que seria a natureza humana - e a educação/escola transformaria a criança em um adulto livre e pensante guiado, no mundo, pela razão em busca de uma vivência cidadã; ao passo que o professor deveria formar o aluno para o dever cívico e a virtude.

No tocante ao estágio da sociedade do trabalho, conforme Ghiraldelli Jr. (1997), a infância equivaleria à fase da vida propícia à aproximação da vida humana real; nesse estágio social a educação deveria transformar a criança num adulto trabalhador; cabendo ao professor o papel de integrar as crianças ao mundo constituindo-se em trabalhadores e em profissionais no âmbito do mercado capitalista.

No que tange ao estágio do tecnicismo, Ghiraldelli Jr. (1997) sustenta que "[...] a infância se volatiliza, na medida em que "cada indivíduo é o que é o seu corpo.”' (p. 255); com esse entendimento “[...] se somos corpo, então a educação mais condizente com a nossa condição é o treinamento. Daí o discurso pedagógico se transforma em um discurso exclusivamente técnico: o tecnicismo pedagógico do pós-Guerra e atual.” (p. 255). Na perspectiva do tecnicismo o professor é 
"[...] alguém que lida com meros corpos. [...] Treinar e adestrar jovens para atividades circunscritas [...] para que se atinja a performance ótima.” (p. 256).

Ainda na opinião de Ghiraldelli Jr., a formação do professor na era do tecnicismo é instrumental e não emancipadora, ou seja, o professor é formado para deter as técnicas segundo o adestramento que deve promover:

[...] as técnicas ditas necessárias para o domínio de uma língua, as técnicas para a manipulação de alguma máquina, e mesmo técnicas para a leitura de um texto de filosofia! Sua tarefa, no final, consiste em avaliar as performances alcançadas por seus alunos, destinados, então, a viverem na "sociedade do futuro", que já é a sociedade do presente. (Ghiraldelli Jr., 1997, p. 256)

Outros estudos constataram também essa tendência e buscaram enfrentar o debate na busca da superação da tecnificação da educação. Nessa direção, Devechi e Trevisan (2011) propõem como enfrentamento da formação de professores, numa perspectiva instrumental e não emancipadora, a denominada hermenêutica reconstrutiva, mas, antes, sintetizam o que possibilita tal lógica formativa. Os autores apresentam quatro abordagens teóricas que, partindo da crítica ao cientificismo tradicional, buscam responder aos problemas da política/gestão de formação de professores no Brasil, mas sem efetividade real:

As pós-positivistas, alicerçadas principalmente na teoria hipotético-dedutiva de Popper, na sociologia de Durkheim e na teoria dos jogos de linguagem de Wittgenstein, dedicam-se a alcançar explicações científicas por meio da tentativa de refutação ou confirmação de hipóteses, apostando na autonomia do jogo de linguagem ou da proposição que define a tarefa do professor em relação ao mundo circundante e/ou às relações com os sujeitos que o produzem. As fenomenológico-hermenêuticas, na linha de Husserl, Heidegger, Gadamer, Merleau-Ponty, Paul Ricoeur e Sartre, empenhamse em incentivar a busca da compreensão dos fenômenos educativos por meio de narrativas que visam à sua descrição sistemática pelo docente e à interpretação constante. As dialéticas, desde Marx, Lukács, Gramsci e frankfurtianos, apegam-se à necessidade de o professor desenvolver novas sínteses no confronto entre seu pensamento e o real vivido no contexto social, num processo crítico e transformador da natureza e da sociedade. Já as pós-estruturalistas, baseadas em Nietzsche, Foucault, Derrida e Deleuze-Guattari, chamam atenção para a inserção do discurso da docência no universo efêmero e fragmentário do cotidiano pedagógico, atravessado por múltiplas determinações (ou subjetivações) de poder, gênero, classe, etnia, orientação sexual e cultural. (Devechi \& Trevisan, 2011, p. 410 - grifos nossos)

Os autores propõem a abordagem da Hermenêutica reconstrutiva como forma de corrigir os desvios das quatro abordagens de formação de professor mencionadas. Depreendemos do exposto, que a falta de efetividade na participação dos professores em processo formativo relaciona-se às disputas de concepções teóricas formativas. Nesse sentido, os autores apresentam, baseado na discussão de conhecimento, interesse e ação comunicativa de Habermas, a hermenêutica reconstrutiva [...] como uma perspectiva teórica a ser discutida no tratamento da formação de professores, pois tem como recurso fundamentador a possibilidade de fazer com que a multiplicidade interpretativa possa interagir de modo comunicativo. [...] No enfoque comunicativo, diferentes pesquisadores entram em discussão na tentativa de alcançar soluções, não apenas rápidas e contextualizadas, mas especialmente sustentáveis e abrangentes. (Devechi \& Trevisan, 2011, p. 414) 
Por esse caminho, considerando os interesses técnicos, práticos e emancipatórios, a compreensão da realidade articula-se aos interesses relacionados à ação com a natureza e ao sistema social, repercutindo no entendimento histórico da vida. Assim, os autores advogam a substituição da síntese da consciência pela síntese das experiências vividas que "[...] não é nem um elemento da consciência, nem da pura empiria, mas da experiência prática coletiva.” (Devechi \& Trevisan, 2011, p. 415). Trata-se da unidade da razão percebida por uma multiplicidade de vozes. Por essa via de argumentação,

[...] a partir de um acordo sobre o mundo objetivo, é possível alcançar uma interação

rumo à validade intersubjetiva, em que a força do melhor argumento é elemento crucial da tomada de decisão. Ou seja, o consenso é possível quando os participantes, depois de uma discussão hipotética, obtêm aceitabilidade mútua acerca do argumento mais bem justificado. [...] A verdade passa a ser um problema de argumentação racional que tem como fundo o mesmo mundo objetivo. (Devechi \& Trevisan, 2011, p. 416 - grifo nosso)

Tendo em vista que nessa perspectiva teórica-filosófica "[...] busca-se validar proposições enunciadas por participantes de uma interação que orientam suas ações pelo telos do entendimento” (p. 420), na formação de professores recuperaria a memória, validaria (pelo consenso) as pesquisas e, por meio dos acordos amplos, contemplaria a articulação entre o universal e o singular. Tal formação orientarse-ia por meio de uma disputa racional consensual, tendo a esfera pública, no mundo da vida, como caixa de ressonância. Ressaltamos, entretanto, que embora a perspectiva teórica hermenêutica reconstrutiva defendida seja crítica às outras abordagens teóricas, fica evidente que a formação em tal lógica terá dificuldades em se efetivar (inclusive de emancipar), se considerarmos as contradições e as desigualdades da sociedade capitalista. Se a verdade ocorrerá pela melhor argumentação, qual discurso sobre a formação de professores e sobre o trabalho docente, nessa sociedade, prevalecerá? O discurso da liberdade e da emancipação ou da servidão/alienação?

Enfrentando, mesmo que parcialmente, essa problematização recorremos à reflexão de Rocha (2004) sobre o antagonismo capital e trabalho no qual, por meio da responsabilização individual, o cérebro é colocado a trabalhar. Dessa forma,

O capital fixo mais importante passa a ser o cérebro de quem trabalha, delineiam-se as condições paradoxais da nossa experiência atual: de um lado a servidão voluntária proposta pelo pós-fordismo, de outro um quantum de liberação presente nas linhas de força da virada cognitiva do capital - que trouxe a inteligência para o centro de uma economia imaterial e determinou novas condições para a formação das subjetividades. (Rocha, 2004, p. 154)

Esse antagonismo afetou, fortemente, as reformas do Estado e da educação brasileira e atingiu, igualmente, a política/gestão de formação dos professores e do trabalho docente a partir de 1990, na passagem do fordismo para o pós-fordismo. A esse respeito, sobre o trabalho docente, a lógica da rigidez advinda do antagonismo capital/trabalho cedeu lugar para as relações de trabalho baseadas na autodisciplina permanente e na responsabilização individual da produção e reprodução das diversas práticas sociais como as educacionais. Por esse caminho, o trabalho docente na lógica pósfordista é afetado por uma determinada lógica na qual o trabalho em grupo precisaria

[...] ser estimulado, já que não é espontâneo nem natural, sendo necessário preparar os alunos para a cooperação, e cabendo ao professor fazer parte do time, abrindo mão de seu poder. Pois cabe levar o aluno ao material que serve de suporte para os 
fins educativos, mas cuja aquisição depende do aprendizado singular de cada um. (Rocha, 2004, p. 156)

Embora se defenda o contrário, a dimensão técnica da formação, por essa via argumentativa, parece ter valor em si mesma se consideramos que na era pós-fordista a formação com implicações para o trabalho docente ocorreu com foco no discurso gerencial fornecendo mais do que argumentos para as reformas educacionais em curso desde os anos de 1990. Esse discurso "[...] é o fio da meada de uma renovação do espírito capitalista, por propagar uma nova imagem do pensamento e da inteligência que servirá de base para a neuro-exploração.” (Rocha, 2004, p. 157).

No caso brasileiro, a partir da LDB 9394/1996 (Brasil, 1996), tal política/gestão se efetivou na perspectiva do neoliberalismo em que a flexibilização, diversificação e multidisciplinaridade da formação do trabalhador são apresentadas para superar o modelo fordista, tido como fragmentado e desarticulado em relação à teórica e à prática. Na relação teoria e prática, quando, também, a alma é colocada a trabalhar, em uma sociedade pós-fordista "[...] a educação e o trabalho deixaram de ser momentos distintos da existência individual, pela necessidade de constante atualização dos conhecimentos [...]." (Rocha, 2004, p. 154). Estamos nos referindo à virada cognitiva do capitalismo na qual a produção intelectual foi convertida em economia imaterial na lógica do capital, determinando, dessa forma, as condições para a formação das subjetividades. Assim, o capital fixo fundamental passou a ser o cérebro de quem trabalha e o professor, na realização do trabalho docente, relaciona-se a essa nova lógica formativa.

Seguindo essa lógica de produção social, a educação escolar brasileira passou a se realizar na perspectiva hegemônica da teoria do aprender a aprender, com foco nas competências, habilidades e atitudes. A esse respeito, o trabalhador, a exemplo do professor, ao se qualificar com foco nas competências, responde às demandas formativas requeridas na atualidade, ou seja, busca atender exigências nas quais "[...] a competência é o retorno do trabalho no trabalhador; ou o retorno da atividade profissional no indivíduo." (Rocha, 2004, p. 168). Assim, opera o retorno do trabalho docente no professor na perspectiva do capital humano e do empreendedorismo.

No capitalismo cognitivo, o conhecimento é entendido como a principal forma de valorização do capital, o que exige uma perspectiva formativa pautada por uma intelectualidade difusa que assegura a expansão da economia do conhecimento para a produção e reprodução do capital em geral, assegurando ao indivíduo a garantia de empregabilidade, desde que este se valorize continuamente como capital humano. Como resposta a essa noção de capitalismo cognitivista a política/gestão de formação de professores precisa atender a lógica posta pelo mercado, buscando a instrumentalização técnica do trabalho docente. Assim, para Rocha (2004), a crítica ao modelo de escola que forma para o mercado é pura retórica, sonho iluminista que precisa ser superado e, com esse entendimento, parece assumir a lógica da formação instrumental como a gaiola de ferro de Marx Weber e tantos outros pensadores que veem o capitalismo como o fim da história humana.

É o que testemunham a legislação e a retórica oficial dos administradores do sistema público de ensino. A esse discurso se associa o veredicto de que a função docente é formar cidadãos, supostamente em oposição à instrução utilitária oferecida pelas práticas de escolarização voltadas para o mercado de trabalho. Tudo isso concorreu, e ainda concorre, para a idealização de propostas pedagógicas caracterizadas pela sua dimensão 'crítica', em contraponto aos projetos educacionais oficiais. (Rocha, 2004, p. 169)

Ficamos com a impressão de que a lógica formativa de professores explicitada por Rocha (2004), tem algumas proximidades com a formação na lógica da autoajuda, discutida e criticada por Turmina e Shiroma (2014) que abordam a autoajuda na formação de um novo tipo de trabalhador 
perpassando os séculos XIX, XX e XXI. Referenciadas em Gramsci e Fairclough as autoras identificam os princípios da autoajuda nos relatórios produzidos pela Organização das Nações Unidas para a Educação, a Ciência e a Cultura (UNESCO) e chegam à conclusão de que "[...] a formação de um novo tipo de homem pelo discurso da autoajuda acontece fora, mas também dentro da escola. Ela contribui para a consolidação de novos padrões de sociabilidade burguesa em tempos de neoliberalismo" (p. 255).

Deduz-se que a política/gestão de formação dos professores em tal perspectiva de análise ocorre na lógica da produção flexível, de responsabilização do indivíduo professor, num mundo em mudança, a buscar continuamente a sua formação, visando à empregabilidade no mercado de trabalho - incluindo o trabalho docente - incerto e efêmero. Na visão da Unesco, trata-se de uma formação balizada no aprender a ser para conviver em um mundo diversificado e individualizado que exige a auto formação como resposta ao mundo em mudança. As autoras, nesse sentido, entendem

[...] o discurso de autoajuda como um dos mecanismos que serve às demandas do capital na medida em que contribui para moldar o tipo de trabalhador necessário para atendê-las. Dissemina-se a ideia de que cabe ao indivíduo desenvolver ações para sua inserção e permanência no mercado de trabalho. Educa-se para o desenvolvimento de uma participação cívica, um dos valores da nova sociabilidade forjada pelo neoliberalismo. (Turmina \& Shiroma, 2014, pp. 166-167)

O trabalhador, incluindo o professor na efetivação do trabalho docente, foi chamado a participar do processo educativo de forma compartilhada, ou seja, educar-se "[...] para a superação de si mesmo, para a responsabilização e necessidade de participação de cada um, para o desenvolvimento de virtudes cívicas.” (Turmina \& Shiroma, 2014, p. 176). Trata-se de uma perspectiva em que o indivíduo passa a ser responsável pelo seu próprio destino formativo e, assim, a progredir individualmente como um empresário de si mesmo que se adapta a um mundo incerto e em constante mudança.

No trabalho docente a dimensão científica e técnico-pedagógica é a ponta de lança na disseminação da ideologia da autoajuda que utiliza linguagem simples, afirmativas e práticas, além do método da repetição. No contexto do modelo de produção flexível, depreende-se do estudo de Turmina e Shiroma (2014) que a autoajuda utiliza-se da repetição metódica como estratégia para evidenciar discursivamente um conjunto de palavras - mudança, adaptação, flexibilidade, bemsucedido, comportamento, sucesso, imaginação, medo etc. - inerentes ao incerto mundo em que vivemos.

As fábulas, as metáforas e os jogos são outros instrumentos técnicos utilizados na perspectiva da educação pela autoajuda. A partir de uma experiência prática no ambiente de trabalho, como um jogo ou um diálogo entre amigos, por exemplo, evidencia-se a lógica da motivação e adaptação às mudanças como formas de sobrevida no mundo do trabalho. Em tal exemplo, "[...] mudar atitudes significa enxergar a mudança como importante, sobretudo mantendo o senso de humor, pois 'quem não mudar, morrerá!"' (Turmina \& Shiroma, 2014, p. 175). Requer, assim, novas competências, habilidades e atitudes, valores e emoções para a vivência em um mundo incerto, em que o campo de trabalho, em geral, e do trabalho docente deve ser reinventado.

O foco da autoajuda é a prática de uma linguagem simples que perpassa o senso comum com exemplos, metáforas e fabulas, que traz embutida uma ideologia e visão de mundo caracterizada pela flexibilidade, individualismo, adaptação e pensamento positivo acerca da vida e dos processos educacionais pelos quais o professor é o principal responsável. O foco da educação e da política/gestão de formação de professores nos relatórios da Unesco centra-se na pedagogia do 
aprender a fazer, priorizando, assim, a instrumentalização do trabalho docente. Em tais relatórios, Turmina e Shiroma (2014, pp. 175-176) afirmam terem constatado que

[...] a transformação de conceitos sofisticados em um manual prescritivo para a educação para o século XXI. Para a UNESCO, adquirir conhecimentos não é suficiente para a atuação profissional, é preciso transpô-los para a vida produtiva e social. Nessa perspectiva, à semelhança dos manuais de autoajuda que difundem ideias, propalam exaustivamente jeitos de ser no trabalho. Os referidos relatórios também se dedicam a "ensinar a ser" delineando traços, atributos necessários à formação do trabalhador ideal à reprodução do capital. (Turmina \& Shiroma, 2014, pp. 175-176)

Dessa perspectiva formativa busca-se, como exigência da lógica produtiva flexiva, a formação de um novo homem e, para isso, faz-se necessário um novo tipo de educação individualista e flexível. Nesse sentido, os governos nacionais, como o brasileiro, têm viabilizado as reformas educacionais abrangendo, entre outros aspectos, a formação e o trabalho docente para corrigir as fragilidades formativas priorizando o autodidatismo e as atitudes ativas na aquisição de conhecimentos. $\mathrm{O}$ propósito da política/gestão da formação é, portanto, “[...] educar para a superação de si mesmo, para a responsabilização e necessidade de participação de cada um, para o desenvolvimento de virtudes cívicas.” (Turmina \& Shiroma, 2014, p. 176). Esse discurso foi assumido pela Unesco e passou a influenciar os

[...] currículos, a formação de professores, a organização escolar e a gestão educacional com discurso e ações que visam reformar a educação do século XXI, atribuindo à instituição escolar a 'tarefa de ensinar as futuras gerações a exercer uma cidadania 'de qualidade nova', a partir da qual o espírito de competitividade seja desenvolvido em paralelo ao espírito da solidariedade, por intermédio do abandono da perspectiva de classe. (Turmina \& Shiroma, 2014, p. 177)

Nessa direção formativa, por meio de uma abordagem crítica, Silva (2013), analisa a política/gestão de formação de professores brasileiros na área de Artes. A autora faz a análise na perspectiva da teoria da práxis que considera a história, a classe e a esfera pública como essenciais para a compreensão do real. Depreende-se do estudo de Silva que a formação de professores no Brasil, em geral, busca seus fundamentos na pedagogia do aprender a aprender e na noção de educação flexível que requer um professor mediador do processo de ensino em que o estudante é o ator principal. Nessa lógica,

[...] os educadores perdem o direcionamento da aula, ficam à deriva dos interesses dos alunos, quando na verdade o conhecimento e a experiência do professor precisam estimular os alunos a desejarem aprender a reconhecer a necessidade de um esforço pessoal para incorporar os conhecimentos sistematizados a partir das condições adequadas na escola. (Silva, 2013, p. 18)

A partir do exposto por Silva, depreende-se que a participação dos estudantes, nessa concepção formativa, tem sonegado a efetiva participação dos professores no processo formativo, atribuindo, assim, uma nova lógica ao desenvolvimento do trabalho docente.

Considerando o discurso presente na reforma da educação de 1990, a lógica formativa aventada anteriormente - focada nos critérios da eficiência e eficácia pedagógica -, concorreria para superar as deficiências da formação inicial de professores e deveria abranger, também, a formação continuada e o trabalho docente. Essa política induzida por organismos internacionais tem sido criticada por educadores e pesquisadores da área da educação por considerarem que, em geral, esta 
produz, também, um modelo semelhante de cursos de formação de professores de caráter pontual e aligeirado, realizados com uso de tecnologias em uma lógica neoliberal que

[...] conduz a formação de professores para o interesse de uma rentabilidade na perspectiva do capital. Aliada a esta concepção de produtividade está a finalidade de formar indivíduos funcionais, adaptáveis às demandas do mundo do trabalho e da economia”. [...] O projeto neoliberal propõe o investimento na mudança da prática pedagógica imediata, mais do que num processo de mudança da consciência filosófica. Essa formação, centrada nos aspectos pedagógicos, acontece em menor tempo e o próprio professor se torna o implementador da proposta, fato que auxilia nesse processo de barateamento da educação. (Silva, 2013, pp. 13-14)

No tocante à relação teoria e prática, Silva (2013) revela que os referenciais para a política/gestão de formação de professores e para o trabalho docente no Brasil pautam-se, para além de autores conhecidos como Nóvoa e Perrenoud, nos estudos de Schon e Alarcão. Em Schon busca-se a fundamentação do tripé conhecimento na ação, reflexão na ação e reflexão sobre a ação. Nessa lógica, a "[...] ação é o fim em si, destacando a perda da concepção de práxis, da dialética entre teoria e prática no desenvolvimento do trabalho docente. Conceber a ação separada da reflexão, ou viceversa, nos conduz ou a uma prática reiterativa, mecânica ou a um burocratismo alienante." (Silva, 2013, p. 17) Em Alarcão está presente a dimensão reflexiva, criticada por sua

[...] visão de prática com foco no imediato, pois a reflexão se pauta num contexto de resolver problemas para a prática, como se fosse possível separá-la do todo social ou mesmo do contexto filosófico. Outro aspecto [...] diz respeito ao caráter de formação da prontidão destinado aos cursos de formação inicial. Esse caráter de prontidão, aprender para aplicar, está sintetizado na concepção do aprender a aprender, um jargão bastante popular no âmbito da educação. [...] Como aborda Saviani (2007), a concepção do aprender a aprender nos remete ao ideário pedagógico do Movimento Escola Nova, retirando o eixo do processo educativo, lógico, para os processos psicológicos; dos conteúdos, para os métodos, do professor para o aluno; do esforço, para o interesse; da disciplina, para a espontaneidade [sic]. (Silva, 2013, pp. 17-18)

O estudo de Silva (2013) explicita que a proposta formativa da pedagogia do aprender a aprender é, na contemporaneidade brasileira, hegemônica e impacta as políticas de formação de professores. A autora apresenta a popularização do ideário pedagógico do aprender a aprender por meio de três argumentações:

A primeira delas diz respeito ao fato de se colocar como uma teoria crítica, embora seja de fato uma teoria liberal. A segunda porque responde à necessidade imediata da prática, da ação pedagógica, propondo receitas para soluções pontuais que de fato não resolvem os problemas estruturais. Por último, por contar com a popularidade da teoria de Piaget, que na atualidade tem sido confundida com as contribuições de Vygotsky, embora partam de matrizes teóricas bastante diferenciadas. (Silva, 2013, pp. 18-19)

No enfrentamento teórico-prático de tal ideário formativo, apreende-se de Silva (2013) várias premissas para a formação de professores da área de Arte (mas que podem ser estendidas para outras áreas), das quais destacam-se: 1) a necessidade de domínio do conteúdo específico da área de artes visuais; 2) a necessidade de domínio das metodologias de ensino para apropriação e objetivação do conhecimento compreendendo a participação efetiva dos formandos nas diversas vivências 
formativas em busca da apropriação, dos saberes sistematizados pela humanidade em uma perspectiva democrática; 3) o uso não alienado das tecnologias na educação/escola; e 4) a inclusão escolar por meio do acesso e permanência das crianças na escola.

Objetivamos, no presente texto, discutir a política/gestão de formação de professores no Brasil fazendo um resgate histórico das bases teóricas e filosóficas que a sustentaram, buscando demonstrar que, apesar da diversidade de abordagens, hegemonicamente o processo formativo se mostrou instrumentalista, reducionista e sem a efetiva participação dos próprios docentes no processo formativo. Procuramos refletir sobre o papel da educação na sociedade brasileira, e até mesmo na sociedade capitalista que almeja, em última instância, preparar o indivíduo para o trabalho. Esperamos que o texto contribua com a discussão da formação no âmbito das políticas educacionais, especificamente, no que se refere ao mapeamento da formação de professores e do trabalho docente sob os pontos de vista histórico e teórico-filosófico.

\section{Considerações Finais}

Dos estudos de cunho histórico analisados, depreendemos que a política/gestão de formação de professores no Brasil, tendencialmente, ocorreu na perspectiva da instrumentalização do trabalho docente e a dimensão técnico-pedagógica foi priorizada em relação à político-cultural. Todavia, essa instrumentalização não constituiu-se de forma linear e desprovida das contradições tensionadas pelas forças sociais que vêm lutando por uma educação e pela formação de professores em uma perspectiva libertária e emancipadora.

Nesse sentido, sob o ponto de vista teórico-filosófico, ao lado de uma proposta de instrumentalização do trabalho docente presente na política/gestão de formação de professores, centrada hegemonicamente na formação técnica - na maioria das vezes com o discurso utilitário, forjado na perspectiva individual e adaptativa à esfera privada/mercantil, bem como distanciada da realidade sócio/educacional brasileira -, também ocorreu formação na lógica emancipadora.

Compreendemos, a partir dos artigos estudados, que, historicamente, e sob a forma de contradição e tensionamento, também esteve presente na política/gestão de formação de professores, como resistência, a perspectiva formativa emancipadora. Esta buscou efetivar embora encontrando dificuldades - uma lógica de educação balizada no entendimento: da classe, esfera pública/nacional-popular; da democracia substantiva de participação efetiva, na qual a eficiência e eficácia educacional foi pensada subsumida à efetividade política e cultural; da filosofia da práxis, fundamentada na noção de superação constante das fraturas da sociedade capitalista referente, à filosofia, história e política, ao materialismo histórico e materialismo dialético, à estrutura e superestrutura e à teoria e prática (Gramsci, 2006).

A presente reflexão histórico-filosófica parece ser um ponto de partida importante para pensarmos e agirmos acerca da política/gestão de formação de professores e os impactos para o trabalho docente no Brasil abrangendo as abordagens cultural e político-educacional como dimensões a serem dialeticamente articuladas no âmbito da política/gestão de formação inicial e formação continuada dos licenciados para ser professores no Brasil.

A reflexão sobre a concepção formativa que fundamenta historicamente a política/gestão de professores e do trabalho docente no Brasil, nesse sentido, revela a predominância econômicocorporativa e técnico-pedagógica e, contraditoriamente, também, apresenta argumentos formativos de cunho ético-político e político-cultural. A reflexão sobre essa contradição na formação do professor é profícua para explicitar os elementos de instrumentalização técnico-pedagógica do trabalho decente e vislumbrar uma perspectiva formativo mais substantiva. 


\section{Referências}

Bardin, L. (1977). Análise de conteúdo. Lisboa/Portugal: Edições 70.

Brasil (1961). Lei 4.024, de 20 de dezembro de 1961. Fixa as Diretrizes e Bases da Educação

Nacional. Brasília/DF, Diário Oficial da União - Seção 1, 27 dez.

Brasil (1968). Lei no 5.540 de 28 de novembro de 1968. Diário oficial da União, Brasília: Câmara dos

Deputados, p. 10369, 28 de nov.

Brasil (1971). Lei 5.692/71, de 11 de agosto de 1971. Diário Oficial da União, Brasília, 12 ago.

Brasil (1996). Lei Federal n. 9.394, de 20 de dezembro de 1996. Estabelece as diretrizes e bases da educação nacional. Brasília, Diário Oficial da União, 23 dez.

Brzezinski, I. (1987). A formação do professor para o início da escolarização. Goiânia: Ed. UCG/SE.

Brzezinski, I., \& Garrido, E. (2001). Análise dos trabalhos do GT Formação de Professores: O que revelam as pesquisas do período 1992-1998. Revista Brasileira de Educação, s./ v.,(18), 82-101. https://doi.org/10.1590/S1413-24782001000300008

Candau, V. M. F. (Coord.) (1987). Novos rumos da licenciatura. Brasília: INEP.

Candau, V. M. F. (Org.) (1997). Magistério, construção cotidiana. Petrópolis: Vozes.

Cavalcante, M. J. (1994). CEFAM: Uma alternativa pedagógica para a formação do professor. São Paulo: Cortez.

Catani, D. B. et al (Orgs.) (1997). Docência, memória e gênero: Estudos sobre formação. São Paulo: Escrituras Editora.

Devechi, C. P. V. \& Trevisan, A. L. (2011). Abordagens na formação de professores: Uma reconstrução aproximativa do campo conceitual. Revista Brasileira de Educação, 16(47), 409426. https://doi.org/10.1590/S1413-24782011000200008

Durkheim, E. (1977). The evolution of educational thought. Lectures on the formation and development of secondary education in France. London: RKP.

Gatti, B. A. (1997). Formação de professores e carreira: Problemas e movimentos de renovação. Campinas: Autores Associados.

Gatti, B. A. (2012). Formação de professores e profissionalização: Contribuições dos estudos publicados na Rbep entre 1998 e 2011. Revista Brasileira de Estudos Pedagógicos, 93(234), 423442. https://doi.org/10.24109/2176-6681.rbep.93i234.448

Ghiraldelli Jr. P. (1997). O que é um "bom professor"? O professor no discurso pedagógico do mundo moderno e contemporâneo. Revista Educação e Filosofia, 11(21/22), 245-262.

Gramsci, A. (2006). Cardernos do Cárcere (4. ed., C. N. Coutinho, Trad.). Rio de Janeiro: Civilização Brasileira.

Marx, K. (1982). Para a crítica da economia política; salário, preço e lucro; o rendimento e suas fontes: A economia vulgar. (E. Malagodi, L. Konder, J. Giannotti \& A. Rehfeld, Trads.) São Paulo: Abril Cultural.

Marx, K. (1985). O capital (2. ed., Barbosa, R. \& Kothe, F. R., Trads.) São Paulo: Nova Cultural.

Mcculloch, G. (2012). História da educação e formação de professores. Revista Brasileira de Educação, 17(49), 121-132. https://doi.org/10.1590/S1413-24782012000100007

Mello, G. N. de (2003). Magistério de $1^{\circ}$ Grau: Da competência técnica ao compromisso politico. (13. ed.) São Paulo: Cortez.

Menezes, L. C. de (1996). Professores: Formação e profissão. Campinas/São Paulo/NUPES: Autores Associados.

Mendes, O. M. (2002). A formação de professores no contexto educacional brasileiro. Revista Educação e Filosofia, 16(31), 75-91.

Mortatti, M. R. L. (2008). Notas para uma história da formação do alfabetizador no Brasil. Revista Brasileira de Estudos Pedagógicos, 89(223), 467-476. 
Nóvoa, A. (Org.) (1995). Profissão professor. Porto: Porto Editora.

Revista Brasileira de Educação (s.d.). Acesso em 29 de Agosto, 2019, de http:/ / www.scielo.br/scielo.php?script=sci_serial\&pid=1413-2478\&lng=pt\&nrm=iso.

Revista Brasileira de Estudos Pedagógicos (s.d.). Acesso em 29 de Agosto, 2019, de http://rbepold.inep.gov.br/index.php/rbep.

Revista Digital Arte\& Educação - Cultura - Formação - Comunicação - Produção (s.d.). Acesso em 29 de Agosto, 2019, de http:/ / revistadigitalart.blogspot.com.

Revista Educação e Filosofia (s.d.). Acesso em 29 de Agosto, 2019, de http:/ /www.seer.ufu.br/index.php/EducacaoFilosofia.

Rocha, M. (2004). Paradoxo da formação: Servidão voluntária e liberação. Revista Brasileira de Educação, s./v.(27), 154-212. https://doi.org/10.1590/S1413-24782004000300011

Saviani, D. (2008). A pedagogia no Brasil: História e teoria. Campinas: Autores Associados.

Saviani, D. (2009). Formação de professores: Aspectos históricos e teóricos do problema no contexto brasileiro. Revista Brasileira de Educação, 14(40), 143-155. https://doi.org/10.1590/S1413-24782009000100012

Silva Jr. J. R. (2003). Reformas do Estado e da educação e as políticas públicas para a formação de professores a distância: Implicações políticas e teóricas. Revista Brasileira de Educação, s./v.(24), 78-94. https://doi.org/10.1590/S1413-24782003000300007

Silva, R. N. et al (1991). Formação de professores no Brasil: Um estudo analítico e bibliográfico. São Paulo: Fundação Carlos Chagas, REDUC.

Silva, M. C. R. F. (2013) Formação docente em arte: da formação nas licenciaturas à formação continuada. Revista Digital Arte ¿ Educação - Cultura - Formação - Comunicação - Produção, XI(14), 01-28. Acesso em 29 de Setembro, 2017, de http://www.revista.art.br/site-numero14/isabela-frade.pdf.

Rugiu, A. S. (1998). Nostalgia do mestre artesão. Campinas: Autores Associados.

Tanuri, L. M. (2000). História da formação de professores. Revista Brasileira de Educação, s./v.(14), 62 89.

Tardif, M. (2002). Saberes docentes e formação profissional. Petrópolis, RJ: Vozes.

Turmina, A. C., \& Shiroma, E. O. (2014). "Se você não mudar, morrerá": A (con)formação de um trabalhador de novo tipo no discurso de autoajuda. Revista Brasileira de Educação, 19(56), 165 180. https://doi.org/10.1590/S1413-24782014000100009 


\section{Sobre os Autores}

\section{Roberto Francisco de Carvalho}

Universidade Federal do Tocantins - UFT/Brasil

rcarvalho@uft.edu.br http://orcid.org/0000-0001-7278-181X

PhD em Políticas Públicas e Formação Humana (Universidade do Estado do Rio de Janeiro/UERJ); Doutor e Mestre em Educação pela Universidade Federal de Goiás (UFG); Professor Adjunto da Universidade Federal do Tocantins (UFT)/Campus Universitário de Palmas - Cursos de Filosofia e Teatro; Membro do corpo docente do Mestrado Profissional em Educação da UFT (PPPGE); Pesquisador na área de Currículo, Política e Gestão Educacional, vinculado ao Grupo de Estudo e Pesquisa Práxis Socioeducativa e Cultural (Líder) e Grupo de Estudo, Pesquisa e Extensão em Educação Municipal da UFT e Observatório dos Sistemas e Planos de Educação no Tocantins (EpeEM/ObsSPE) e Rede Universitas/Br.

\section{Rosilene Lagares}

Universidade Federal do Tocantins - UFT/Brasil.

roselagares@uft.edu.br http://orcid.org/0000-0003-2959-5573

Pós-doutora em Educação pela Universidade do Oeste de Santa Catarina (Unoesc), Doutora e Mestre em Educação pela Universidade Federal de Goiás (UFG); Professora Adjunto da Universidade Federal do Tocantins (UFT)/Campus de Palmas/Curso de Pedagogia e Programa de Pós-Graduação em Educação (Acadêmico e Profissional); Professora do Curso de Doutorado em Educação da Rede EducaNorte; É líder e pesquisadora do grupo de pesquisa CNPq/Plataforma Lattes/UFT: Grupo de Estudos e Pesquisas em Políticas Curriculares e Educativas (Gepce); Pesquisadora do Grupo Educação, Políticas Públicas e Cidadania; Coordenadora do Subgrupo de Estudo, Pesquisa e Extensão em Educação Municipal na UFT (EpeEM), do Observatório de Sistemas e Planos de Educação do Tocantins (ObsSPE) e da Pesquisa Rede MAPA.

\section{Doracy Dias Aguiar de Carvalho}

Universidade Federal do Tocantins - UFT-UNB/Brasil

doracy@uft.edu.br

https://orcid.org/0000-0001-6992-1615

Doutoranda em Política Social pela Universidade de Brasília (UNB); Mestre em Educação pela Universidade Federal de Goiás (UFG). Assistente Social da Universidade Federal do Tocantins (UFT). Membro do Grupo de Pesquisa Práxis Socioeducativa e Cultural da UFT e do Grupo de Estudo e Pesquisa sobre Democracia, Sociedade Civil e Serviço Social. (GEPEDSS/UNB). 


\title{
Sobre as Editoras Convidas
}

\author{
Deise Mancebo \\ Universidade do Estado do Rio de Janeiro \\ deise.mancebo@gmail.com \\ http://orcid.org/0000-0001-8312-4495 \\ Doutora em Educação pela Pontifícia Universidade Católica de São Paulo. Professora Titular da \\ Universidade do Estado do Rio de Janeiro. Pesquisadora e professora do Programa de Pós- \\ graduação em Políticas Públicas e Formação Humana. Coordenadora da Rede Universitas/Br.
}

\section{Kátia Maria Teixeira Santorum}

Universidade do Estado do Rio de Janeiro

katia.santorum@gmail.com

https://orcid.org/0000-0003-2830-157X

Doutora em Saúde Pública pela Escola Nacional de Saúde Pública Sérgio Arouca / Fundação Oswaldo Cruz (Fiocruz). Professora Adjunta da Universidade do Estado do Rio de

Janeiro. Pesquisadora e professora do Programa de Pós-graduação em Políticas Públicas e Formação Humana.

\section{Carla Vaz dos Santos Ribeiro}

Universidade Federal do Maranhão

carlavazufma@gmail.com

http://orcid.org/0000-0002-5518-9619

Doutora em Psicologia Social pela Universidade do Estado do Rio de Janeiro. Professora Associada da Universidade Federal do Maranhão. Pesquisadora e professora do Programa de Pós-graduação em Psicologia da UFMA. Integrante da Rede Universitas/Br.

\section{Denise Bessa Léda}

Universidade Federal do Maranhão

denise.bessa.leda@gmail.com

http://orcid.org/0000-0002-8696-6126

Doutora em Psicologia Social pela Universidade do Estado do Rio de Janeiro. Professora da Universidade Federal do Maranhão. Professora permanente e pesquisadora do Programa de PósGraduação em Psicologia da Universidade Federal do Maranhão. Membro da Rede Universitas/Br e do Grupo de Pesquisa Psicodinâmica e Clínica do Trabalho da Associação Nacional de Pesquisa e Pós-graduação em Psicologia. 


\section{Dossiê Especial O Trabalho no Ensino Superior arquivos analíticos de políticas educativas}

Volume 28 Número 15

20 de janeiro 2020

ISSN 1068-2341

\section{(c) (i) (2)}

Los/as lectores/as pueden copiar, mostrar, distribuir, y adaptar este articulo, siempre y cuando se de crédito y atribución al autor/es y a Archivos Analíticos de Políticas Educativas, los cambios se identifican y la misma licencia se aplica al trabajo derivada. Más detalles de la licencia de Creative Commons se encuentran en https://creativecommons.org/licenses/by-

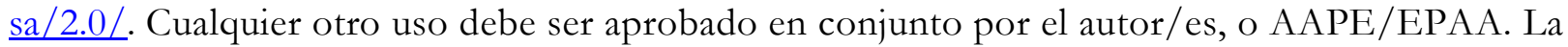
sección en español para Sud América de AAPE/EPAA es publicada por el Mary Lou Fulton Teachers College, Arizona State University y la Universidad de San Andrés de Argentina. Los artículos que aparecen en AAPE son indexados en CIRC (Clasificación Integrada de Revistas Científicas, España) DIALNET (España), Directory of Open Access Journals, EBSCO Education Research Complete, ERIC, Education Full Text (H.W. Wilson), PubMed, QUALIS A1 (Brazil), Redalyc, SCImago Journal Rank, SCOPUS, SOCOLAR (China).

Por errores y sugerencias contacte a Fischman@asu.edu

Síganos en EPAA's Facebook comunidad at https://www.facebook.com/EPAAAAPE y en Twitter feed@epaa_aape. 


\section{arquivos analíticos de políticas educativas conselho editorial}

Editor Consultor: Gustavo E. Fischman (Arizona State University)

Editoras Associadas: Andréa Barbosa Gouveia (Universidade Federal do Paraná), Kaizo Iwakami Beltrao, (Brazilian School of Public and Private Management - EBAPE/FGVl), Sheizi Calheira de Freitas (Federal University of Bahia), Maria Margarida Machado, (Federal University of Goiás / Universidade Federal de Goiás), Gilberto José Miranda, (Universidade Federal de Uberlândia, Brazil), Marcia Pletsch, Sandra Regina Sales (Universidade Federal Rural do Rio de Janeiro)

\author{
Almerindo Afonso \\ Universidade do Minho \\ Portugal
}

Rosanna Maria Barros Sá

Universidade do Algarve

Portugal

\section{Maria Helena Bonilla \\ Universidade Federal da Bahia \\ Brasil}

Rosa Maria Bueno Fischer Universidade Federal do Rio

Grande do Sul, Brasil

Alice Casimiro Lopes

Universidade do Estado do Rio de

Janeiro, Brasil

\section{Suzana Feldens Schwertner Centro Universitário Univates Brasil}

Geovana Mendonça Lunardi Mendes Universidade do Estado de Santa Catarina

Flávia Miller Naethe Motta

Universidade Federal Rural do Rio de Janeiro, Brasil

Alexandre Fernandez Vaz

Universidade Federal de Santa

Catarina, Brasil

Regina Célia Linhares Hostins

Universidade do Vale do Itajaí,

Brasil

\section{Alfredo Macedo Gomes \\ Universidade Federal de \\ Pernambuco Brasil}

Jefferson Mainardes

Universidade Estadual de Ponta

Grossa, Brasil

Jader Janer Moreira Lopes

Universidade Federal Fluminense

e Universidade Federal de Juiz de Fora, Brasil

\section{Debora Nunes \\ Universidade Federal do Rio \\ Grande do Norte, Brasil}

Alda Junqueira Marin

Pontifícia Universidade Católica de São Paulo, Brasil

Dalila Andrade Oliveira

Universidade Federal de Minas

Gerais, Brasil
José Augusto Pacheco

Universidade do Minho, Portugal

Jane Paiva

Universidade do Estado do Rio de Janeiro, Brasil

Paulo Alberto Santos Vieira Universidade do Estado de Mato Grosso, Brasil

Fabiany de Cássia Tavares Silva Universidade Federal do Mato Grosso do Sul, Brasil

\section{António Teodoro}

Universidade Lusófona

Portugal

\section{Lílian do Valle}

Universidade do Estado do Rio de Janeiro, Brasil

\author{
Alfredo Veiga-Neto \\ Universidade Federal do Rio \\ Grande do Sul, Brasil
}




\section{archivos analíticos de políticas educativas consejo editorial}

Editor Consultor: Gustavo E. Fischman (Arizona State University)

Editores Asociados: Felicitas Acosta (Universidad Nacional de General Sarmiento, Argentina), Armando Alcántara Santuario (Universidad Nacional Autónoma de México), Ignacio Barrenechea, Jason Beech (Universidad de San Andrés), Angelica Buendia, (Metropolitan Autonomous University), Alejandra Falabella (Universidad Alberto Hurtado, Chile), Carolina Guzmán-Valenzuela (University of Chile), Veronica Gottau (Universidad Torcuato Di Tella), Antonio Luzon, (Universidad de Granada), José Luis Ramírez, (Universidad de Sonora), Paula Razquin, Axel

Rivas (Universidad de San Andrés), Maria Veronica Santelices (Pontificia Universidad Católica de Chile), Maria Alejandra Tejada-Gómez (Pontificia Universidad Javeriana, Colombia)

Claudio Almonacid

Universidad Metropolitana de

Ciencias de la Educación, Chile

Miguel Ángel Arias Ortega

Universidad Autónoma de la

Ciudad de México

Xavier Besalú Costa

Universitat de Girona, España

Xavier Bonal Sarro Universidad

Autónoma de Barcelona, España

Antonio Bolívar Boitia

Universidad de Granada, España

José Joaquín Brunner Universidad Diego Portales, Chile

Damián Canales Sánchez

Instituto Nacional para la

Evaluación de la Educación, México

Gabriela de la Cruz Flores

Universidad Nacional Autónoma de México

Marco Antonio Delgado Fuentes

Universidad Iberoamericana, México

Inés Dussel, DIE-CINVESTAV, México

Pedro Flores Crespo Universidad Iberoamericana, México
Ana María García de Fanelli

Centro de Estudios de Estado y

Sociedad (CEDES) CONICET,

Argentina

Juan Carlos González Faraco

Universidad de Huelva, España

María Clemente Linuesa

Universidad de Salamanca, España

Jaume Martínez Bonafé

Universitat de València, España

Alejandro Márquez Jiménez

Instituto de Investigaciones sobre la Universidad y la Educación, UNAM, México

María Guadalupe Olivier Tellez, Universidad Pedagógica Nacional, México

Miguel Pereyra Universidad de

Granada, España

Mónica Pini Universidad Nacional de San Martín, Argentina

Omar Orlando Pulido Chaves Instituto para la Investigación Educativa y el Desarrollo Pedagógico (IDEP)

José Ignacio Rivas Flores

Universidad de Málaga, España
Miriam Rodríguez Vargas

Universidad Autónoma de

Tamaulipas, México

José Gregorio Rodríguez

Universidad Nacional de Colombia, Colombia

Mario Rueda Beltrán Instituto de Investigaciones sobre la Universidad y la Educación, UNAM, México

José Luis San Fabián Maroto Universidad de Oviedo, España

Jurjo Torres Santomé, Universidad de la Coruña, España

Yengny Marisol Silva Laya

Universidad Iberoamericana, México

Ernesto Treviño Ronzón

Universidad Veracruzana, México

Ernesto Treviño Villarreal

Universidad Diego Portales Santiago, Chile

Antoni Verger Planells Universidad Autónoma de Barcelona, España

Catalina Wainerman

Universidad de San Andrés, Argentina

Juan Carlos Yáñez Velazco

Universidad de Colima, México 


\section{education policy analysis archives editorial board}

Lead Editor: Audrey Amrein-Beardsley

Editor Consultor: Gustavo E. Fischman (Arizona State University)

Associate Editors: Melanie Bertrand, David Carlson, Lauren Harris, Eugene Judson, Mirka Koro-Ljungberg, Daniel Liou, Scott Marley, Molly Ott, Iveta Silova (Arizona State University)

Cristina Alfaro

San Diego State University

Gary Anderson

New York University

Michael W. Apple

University of Wisconsin, Madison

Jeff Bale

University of Toronto, Canada

Aaron Bevanot SUNY Albany

David C. Berliner

Arizona State University

Henry Braun Boston College

\section{Casey Cobb}

University of Connecticut

Arnold Danzig

San Jose State University

Linda Darling-Hammond

Stanford University

Elizabeth H. DeBray

University of Georgia

David E. DeMatthews

University of Texas at Austin

Chad d'Entremont Rennie Center

for Education Research \& Policy

John Diamond

University of Wisconsin, Madison

Matthew Di Carlo

Albert Shanker Institute

Sherman Dorn

Arizona State University

Michael J. Dumas

University of California, Berkeley

Kathy Escamilla

University ofColorado, Boulder

Yariv Feniger Ben-Gurion

University of the Negev

Melissa Lynn Freeman

Adams State College

Rachael Gabriel

University of Connecticut
Amy Garrett Dikkers University

of North Carolina, Wilmington

Gene V Glass

Arizona State University

Ronald Glass University of

California, Santa Cruz

Jacob P. K. Gross

University of Louisville

Eric M. Haas WestEd

Julian Vasquez Heilig California

State University, Sacramento

Kimberly Kappler Hewitt

University of North Carolina

Greensboro

Aimee Howley Ohio University

Steve Klees University of Maryland

Jaekyung Lee SUNY Buffalo

Jessica Nina Lester

Indiana University

Amanda E. Lewis University of

Illinois, Chicago

Chad R. Lochmiller Indiana

University

Christopher Lubienski Indiana

University

Sarah Lubienski Indiana University

William J. Mathis

University of Colorado, Boulder

Michele S. Moses

University of Colorado, Boulder

Julianne Moss

Deakin University, Australia

Sharon Nichols

University of Texas, San Antonio

Eric Parsons

University of Missouri-Columbia

Amanda U. Potterton

University of Kentucky

Susan L. Robertson

Bristol University
Gloria M. Rodriguez

University of California, Davis

R. Anthony Rolle

University of Houston

A. G. Rud

Washington State University

Patricia Sánchez University of

University of Texas, San Antonio

Janelle Scott University of

California, Berkeley

Jack Schneider University of

Massachusetts Lowell

Noah Sobe Loyola University

Nelly P. Stromquist

University of Maryland

Benjamin Superfine

University of Illinois, Chicago

Adai Tefera

Virginia Commonwealth University

A. Chris Torres

Michigan State University

Tina Trujillo

University of California, Berkeley

Federico R. Waitoller

University of Illinois, Chicago

Larisa Warhol

University of Connecticut

John Weathers University of

Colorado, Colorado Springs

Kevin Welner

University of Colorado, Boulder

Terrence G. Wiley

Center for Applied Linguistics

John Willinsky

Stanford University

Jennifer R. Wolgemuth

University of South Florida

Kyo Yamashiro

Claremont Graduate University

Miri Yemini

Tel Aviv University, Israel 